\title{
THE CLIFFORDIAN VIRTUE
}

\author{
BRIAN ZAMULINSKI
}

University of Saskatchewan

\begin{abstract}
There is a case to be made for the contention that it is a virtue to have a disposition to try to conform to W. K. Clifford's ethics of belief. The arguments are not Clifford's own but new deductive ones. There is also a discussion of some recent criticisms of Clifford. They seldom succeed against Clifford's original position and never succeed against the case for the Cliffordian virtue. It is pointed out that there need be no conflict between religion and Cliffordianism. The virtue approach emphasizes the value of striving over the value of success.
\end{abstract}

W. K. Clifford's ethics of belief is encapsulated in his slogan, 'It is wrong always, everywhere, and for anyone, to believe anything upon insufficient evidence. ${ }^{1} \mathrm{He}$ has arguments for his position that are often under-estimated. Nevertheless, instead of trying to explain and support Clifford's own arguments, this paper will recast the case for the ethics of belief as a case for the development and maintenance of a virtue. Some philosophers have taken Clifford's views to be deontological, ${ }^{2}$ relying on statements like Clifford's declaration that 'when an action is once done, it is right or wrong for ever; no accidental failure of its good or evil fruits can possibly alter that. ${ }^{3}$ But not everything that Clifford says can be described as deontological. Someone who wanted to characterize him as primarily a virtue theorist could point to his declaration that 'we all suffer severely

${ }^{1}$ William Kingdon Clifford, 'The Ethics of Belief', in his Lectures and Essays, Vol. 2 (London: MacMillan \& Co., 1879), pp. 177-211 (p. 186).

${ }^{2}$ See Jan Vorstenbosch, 'W.K. Clifford's Ethics of Belief Revisited', in Anthoine Meijers, ed., Belief, Cognition, and the Will (Tilberg: Tilberg University Press, 1999), pp. 99-111.

${ }^{3}$ Clifford, 'The Ethics of Belief', p. 178. 
enough from the maintenance and support of false beliefs and the fatally wrong actions which they lead to, and the evil born when one such belief is entertained is great and wide. But a greater and wider evil arises when the credulous character is maintained and supported ... ${ }^{4}$ But this paper is not an attempt to determine the best interpretation of Clifford.

Whatever the most plausible interpretation of Clifford himself may be, the Cliffordian virtue is, obviously enough, the disposition to do that which minimizes the probability that one will believe without sufficient evidence, or an adequate substitute for sufficient evidence. And this paper is an argument to the effect that we ought to develop and exercise the Cliffordian virtue - it is ethics, not exegesis. Naturally, developing and exercising it does not mean that the doxastically virtuous individual will necessarily achieve the morally optimal state of avoiding all over-belief anymore than being courageous means that the courageous individual will always be victorious. When it comes to virtues like courage and the Cliffordian virtue, what matters in the moral assessment of individuals is their striving and not their successes: if people are blameworthy, it is not because they have failed but because they have not tried. It is worthwhile making a case for the Cliffordian virtue because, despite a century of questionable objections, it is morally important to try to avoid over-believing.

The case for the Cliffordian virtue consists of two sets of sound, deductive arguments, three arguments in each set, which will all be set out in standard form. Presenting the arguments in standard form has the advantage that it will be clear what kind of evidence could potentially count against them. The first argument in the first set will be to the effect that we should try to avoid believing a specified subset of false propositions. The second will conclude that the only way to achieve that goal is to try to avoid over-believing. The third will specify the ways in which we can try to avoid over-believing, blocking the objection that we do not have an obligation to avoid over-believing because we cannot do so. The second set of arguments will show that the fact that we should try to acquire relevant truths also supports the conclusion that we should try to avoid over-believing. After arguing positively for the Cliffordian virtue, there will be an examination of some contemporary anti-Cliffordian arguments. It will be shown that they fail to undermine the case for the Cliffordian virtue.

\footnotetext{
${ }^{4}$ Clifford, 'The Ethics of Belief', p. 185.
} 


\section{THE CASE FOR THE CLIFFORDIAN VIRTUE}

The case for the Cliffordian virtue starts with the observation that there are some acts that a person should not perform. Suppose that it is wrong to perform a particular act but that it is permissible to believe anything at all. Suppose also that an agent has a desire to act in a morally acceptable or praiseworthy way. Since the agent's acts are apparently determined by his desires and beliefs - barring inability or intervention - the agent's possessing an appropriate array of false beliefs will result in his performing the wrongful act in some sets of circumstances. To take a fictitious example, it is wrong to restrain someone and deliberately to inflict superficial wounds on him with a knife but if someone believed that the person whom he was pricking or slashing was possessed by a demon, that being possessed was an undesirable condition, and that pricking or slashing the possessed was an essential aspect of an exorcism ritual, then he might very well restrain the person and slash him, his abilities and circumstances permitting. If the exorcist's beliefs were true, he would be benefitting the person whom he was cutting. Subjectively he would be doing good, while objectively he would be doing evil.

We use the foregoing kind of explanation for actions all the time. Generalizing, if it is permissible to believe anything at all, then it is permissible to do anything at all. For any act, someone with unobjectionable or even praiseworthy desires, and with the ability and freedom to act, would perform it, provided he had the right constellation of beliefs, that is, the relevant delusions if true beliefs would not serve. If there were no moral restrictions on what he could believe, there would be no moral restrictions on what he could do. Because of the apparent causal relationship between beliefs and acts, it is self-contradictory to declare that some acts are impermissible but to say that no beliefs are. Since beliefs and (good) desires apparently cause actions, the fact that some acts are forbidden entails that some beliefs are forbidden. Of course, it is improbable that a person will actually do absolutely anything at all, because there are prudential reasons for acquiring many true beliefs and for avoiding many false ones, but it would still be morally permissible in principle for him to do anything at all.

It does not follow that all false beliefs will result directly and immediately in the believer performing wrongful acts. Nor does the case for the Cliffordian virtue depend on all false beliefs having that effect, anymore than Clifford's original argument did. Hence, it will be assumed that 
the fundamental problem is that some false beliefs have the potential to result in the believer performing wrongful acts. It will take an argument to show that the best way to deal with them is by means of forbidding all unwarranted beliefs. The first part of the argument is as follows.

1a) People have moral obligations, which they naturally should fulfil.

1b) Some false beliefs sometimes result in people failing to fulfil their moral obligations.

1c) Therefore, people should try to avoid acquiring false beliefs that would result in their failing to fulfil their moral obligations.

The conclusion follows validly from the premises because, otherwise, it would be permissible for people to be reckless when it comes to fulfilling their moral obligations, which is self-contradictory. Taking it for granted that we have moral obligations, we have an obligation to do something about what we believe, if we are able to. That leaves the second premise.

Examples suffice to demonstrate that the second premise is true, the claim being that false beliefs sometimes have a morally deleterious effect, not that they always do. In 1932, there was a famine in Ukraine and, less severely, in other parts of the Soviet Union. Tens of millions of people were deliberately starved, which makes it the greatest case of mass torture in history, and several million died. But, in the official view, 'people who appeared to be innocent were to be seen as guilty. A peasant slowly dying of hunger was, despite appearances, a saboteur working for the capitalist powers in their campaign to discredit the Soviet Union. ${ }^{5}$ A decade later, Hitler believed that it was a worldwide Jewish conspiracy that had brought the UK, the USA, and the USSR into war with Germany, that 'Jews were the aggressors, Germans the victims', and inferred that, 'if disaster were to be averted, Jews would have to be eliminated.' This madness resulted in the ultimate decision to implement the Holocaust. ${ }^{7}$ In both cases, false beliefs facilitated evil acts of great enormity. In both cases, the evils would not have happened but for the beliefs. Many more examples can be adduced, although the evil is not always on the same scale. For instance, there are people in Uganda who apparently believe

${ }^{5}$ Timothy Snyder, Bloodlands: Europe between Hitler and Stalin (New York: Basic Books, 2010), p. 41.

${ }^{6}$ Snyder, Bloodlands, p. 214.

7 Gord McFee, 'When Did Hitler Decide on the Final Solution', in The Holocaust History Project, 1999, available at: <http://www.holocaust-history.org/hitler-finalsolution/> [accessed 18/12/2011]. 
that child sacrifice can enable the 'beneficiary' of the sacrifice to achieve his goals. ${ }^{8}$ People strive for success everywhere but sacrifice children in its pursuit only where the relevant beliefs exist. In view of the foregoing examples, the second premise of the first argument is clearly true and, given that we are taking for granted that we have moral obligations, we can accept the conclusion as true and use it as a premise in a second deductive argument.

2a) People should try to avoid acquiring false beliefs that would result in their failing to fulfil their moral obligations.

2b) The only way for people to try to avoid acquiring such false beliefs is to try to avoid believing any propositions without sufficient evidence, or an adequate substitute for sufficient evidence.

2c) Therefore, people should try to avoid over-believing entirely.

The conclusion follows because, otherwise, it would at least sometimes be permissible for people not to fulfil their moral obligations, which is self-contradictory. Since the first premise is the conclusion of the preceding argument, what we need to do is to demonstrate that the second premise is true. As for that premise, any alternative to avoiding over-believing entirely would be a three-step process that involved a person first noting that a proposition is not supported by sufficient evidence or an adequate substitute, then determining that overbelieving the proposition would not result in his failing to fulfil his moral obligations, and finally proceeding deliberately to over-believe it. But we cannot levitate or walk through walls, and no more can we deliberately bring ourselves to over-believe propositions when we have ourselves established that they are not supported by sufficient evidence or an adequate substitute and that believing them will have no morally untoward effects. It follows that if there are any moral restrictions on what people are permitted to believe, then it must be the case that they have to try to avoid over-believing entirely. There are moral restrictions on what people may believe, as the first argument showed. Therefore, people have to avoid over-believing entirely.

A potential objection at this point is that there is insufficient evidence for the contention that we lack the ability deliberately to over-believe when the specified conditions obtain. Proponents of a purported 'right

8 'Where Child Sacrifice Is a Business', BBC News, 11 October 2011, available at: $<$ http://www.bbc.co.uk/news/world-africa-15255357> [accessed 18/12/2011]. 
to believe' might proclaim that it follows that we do not have sufficient evidence to justify believing that the Cliffordian position is true and, therefore, that the Cliffordian position is circular. There are two responses. The first is that there is as much evidence that we cannot deliberately over-believe as there is evidence that we cannot levitate and that the amount of evidence therefore is sufficient. The second is that, as Clifford says, 'there are many cases in which it is our duty to act upon probabilities, although the evidence is not such as to justify present belief ..., and that the overwhelming probability is that we cannot deliberately bring ourselves to over-believe something when we know that we lack sufficient evidence for it. Given the probabilities, even if we lack sufficient evidence to justify believing it, we should assume that we lack the ability to over-believe deliberately and adopt the moral policy that is appropriate in view of the assumption. Naturally, we should be willing to revisit the policy if it were ever demonstrated that we have, or can develop, a reliable ability to over-believe propositions for which we know we lack sufficient evidence. Until that time, however, the reasonable and responsible moral policy is to assume that we cannot and to infer that we ought to avoid over-believing entirely. In other words, we can treat the case for the Cliffordian virtue as a matter of practical, not theoretical, reasoning.

It is sometimes claimed that Clifford's ethics of belief presupposes that we can believe voluntarily. Even some Cliffordians accept the claim. ${ }^{10}$ Taken literally, however, the claim is bizarre. To avoid over-believing, it is not necessary to believe but to refrain from believing. The ability we need to adhere to the ethics of belief is not the ability to believe at will but the ability to refrain from believing under the specified conditions. However, to be charitable, the contention may be an awkward way of making the claim that we generally acquire beliefs automatically and cannot prevent ourselves from doing so. None of us can prevent ourselves from acquiring beliefs when we encounter what counts as sufficient evidence, or an adequate substitute for sufficient evidence, in light of our individual standards of evidence. The pertinent question then becomes whether we can exercise any control over our standards of evidence. If we cannot do so, then we cannot do anything that would count as trying

${ }^{9}$ Clifford, 'The Ethics of Belief', p. 189.

${ }^{10}$ Allen Wood, 'The Duty to Believe According to the Evidence', International Journal for the Philosophy of Religion, 63 (2008), 7-24. 
to adhere to the ethics of belief. Since 'ought' implies 'can', it would follow that we have no obligation to avoid over-believing.

Fortunately for the Cliffordian but unfortunately for his opponent, we can intentionally take steps to improve our standards of evidence. In fact, we commonly do so. It is one of the purposes of acquiring an education. And we can intentionally take steps to acquire an education. Educators train nurses, lawyers, physicians, engineers, philosophers and mechanics to make them better at their jobs. As a general rule, the more training and experience someone has, the better are their standards of evidence with respect to a particular field of knowledge. Physicians who specialize are more highly trained than general practitioners and, as a result of the training, better diagnosticians with respect to a specific range of cases. Professional philosophers are better able to judge the validity of arguments than first year students, and the latter become better than people who have never studied philosophy at all. An educated and experienced mechanic is more likely to discover the problem with a vehicle than a newly trained mechanic, and a newly trained mechanic will be better than someone who is untrained. In all such cases, the process of education is intended to result in improved standards of evidence and, in most cases, the process achieves its aim. Moreover, some subjects such as logic and statistics are specifically designed to help us improve our standards of evidence. Our having the capacity to improve our standards of evidence is enough to make us morally responsible for what we believe.

It may appear to some that the argument significantly modifies Clifford's views by adding the phrase 'or an adequate substitute for sufficient evidence'. Clifford's own conclusion does not include such a clause. However, Clifford argues, in the same essay, that it is permissible to accept some propositions on the basis of testimony. If testimony did not count as sufficient evidence, then we would have to infer that Clifford contradicts himself, which would be uncharitable. Of course, it could be argued that testimony is a form of evidence. However, I do not want to enter into disputes as to what constitutes evidence and what does not. Hence, I have added the phrase, 'or an adequate substitute for sufficient evidence'. Reliable testimony counts either as evidence or an acceptable substitute for evidence. The same goes for anything else that gives us adequate reason to believe that a proposition is true. Naturally, to determine whether someone has done what he ought to do in a particular instance will require us to determine whether the grounds for his belief 
constitute either sufficient evidence or an acceptable substitute for sufficient evidence. But we do not need to do that in order to establish - at the more abstract and general level on which we are operating now - that we ought to develop and exercise the Cliffordian virtue.

Contrary to the view expressed in the foregoing paragraph, critics of Clifford sometimes contend that the Cliffordian needs to explain the nature of sufficient evidence (and adequate substitutes for it). This is like asserting that someone who argues that we should try to prevent epidemics has failed to make his case unless he gives a detailed account of the appropriate public health measures. In fact, establishing that we ought to try to prevent epidemics is one thing while designing and developing public health measures is another. Establishing the former contention gives us reason to design and develop the latter. Likewise, establishing the Cliffordian conclusion gives us reason to be concerned about, and to investigate, what constitutes adequate reason to believe. Once the Cliffordian has demonstrated that we have reason to investigate what constitutes adequate reason to believe, however, his job is done. That said, we can now turn to the third argument.

3a) People can improve their standards of evidence generally by studying subjects like logic and statistics, they can gain at least one adequate substitute (on one interpretation of the concept to evidence) by learning to identify real experts whose judgment they can trust, and they can become qualified to judge claims in particular fields through study, investigation, and experience.

3b) People can thereby reduce the probability of their over-believing.

3c) Therefore, people should try to acquire good standards of evidence, to learn how to identify real experts whose judgments they can trust, and to avoid reaching conclusions about subjects they are unqualified to judge.

In short, the Cliffordian does not demand the impossible. On the contrary, his position is common sense. He demands that everyone do what professionals are routinely required to do in order to become, and remain, responsible professionals. Moreover, since the ethics of belief is a matter of avoiding over-belief, adhering to it is easy if one is aware of the kinds of issues that one is not qualified to judge - as professionals are aware of their limitations. As Clifford points out, if someone is too busy to investigate, he is too busy to believe. 
William James correctly affirmed that we need to gain truth as much as to avoid error. However, the existence of this need and the fact that we sometimes over-believe beneficial truths do not entail that over-believing is permissible. Thinking that it does is like trying to justify gambling by pointing out only the wins and ignoring the losses. In actuality, if we license over-belief, we not only license lucky guesses but also denial and delusion, and denial and delusion are not always benign. Given that climate change is going to have seriously deleterious effects on human life on earth, we would indeed take action if we all believed that it would. If over-believing were permissible, however, we would also be morally free to deny it and morally free to believe that we should prepare instead for a Martian invasion. Furthermore, we do not always need specific truths to do what ought to be done - others can substitute for them. We would also take action if we believed that climate change was a serious danger and that it would be too late to prevent the deleterious effects if we waited until we were absolutely certain that they would occur, which would be when they had already occurred. At any rate, the need to gain relevant truths gives us yet another reason to reject over-believing, even when a range of alternative truths will serve equally well when it comes to enabling us to do what we ought to do. In view of the foregoing, the following deductive arguments can be presented without additional explanatory comment.

4a) People have moral obligations.

4b) People's lacking relevant true beliefs sometimes results in their failing to fulfil their moral obligations.

4c) Therefore, people should try to acquire any relevant true beliefs that are necessary for them to fulfil their moral obligations.

5a) People should try to acquire any relevant true beliefs that are necessary for them to fulfil their moral obligations.

$5 b)$ The ways in which to reliably acquire relevant true beliefs include investigation and the seeking out of real experts whose judgment can be trusted.

5b) Therefore, people have an obligation to investigate or to seek out real experts whose judgments they can trust.

6a) Possessing relevant false beliefs will result in the possessor thinking that there is no need to investigate or to seek out a real 
expert, and, hence, in his probably failing to fulfil his obligation to investigate or seek out a real expert.

6b) Over-believing will sometimes result in the possession of relevant false beliefs.

6c) Therefore, in order to keep the way open for the acquisition of relevant true beliefs, people should try to avoid over-believing entirely.

In view of the foregoing arguments, the way in which to show that we have no obligation to develop the Cliffordian virtue is to argue either that it is possible to keep specific beliefs from influencing actions, or that false beliefs never cause us to act immorally, or that we have the ability to induce ourselves to believe propositions when (and even though) we know that we lack sufficient evidence for them, or that we are not capable of improving our standards of evidence, or that one of the first three arguments is invalid. Challenging the second set of arguments would leave in place a conclusive case for the Cliffordian virtue, so we need not particularly concern ourselves with them, but it is doubtful that the critic could show that we never need relevant true beliefs, that false beliefs never prevent the acquisition of relevant truths, or that one or another of the arguments is invalid.

No critic of Cliffordianism has yet challenged the foregoing contentions, of course. Moreover, the extant criticisms of Clifford himself are questionable. It is worthwhile demonstrating that they are dubious, because that will show that common objections to Clifford cannot be adapted for use against the Cliffordian virtue. I take up the task in the following sections, concentrating on recent objections to Cliffordianism.

\section{THE CLIFFORDIAN VIRTUE AND 'EPISTEMIC NORMS'}

Some philosophers contend that the ethics of belief can involve moral, epistemic, or pragmatic norms, maintain that it is important to distinguish the types of norms, and effectively suggest that Clifford's arguments are deficient because he does not explicitly identify and distinguish the norms to which he appeals. In fact, the objection involves gratuitously adding complexity and then complaining that it has not been adequately disentangled. To be specific with these allegations, Andrew Dole and Andrew Chignell write that 'there are ... different kinds of obligation that govern our practices of belief-formation ... The ethicist of belief will 
typically try to specify which kinds, if any, he or she means to ascribe to us." ${ }^{11}$ They contend that 'Clifford and Locke claim that the question of whether one has done one's doxastic best is not only an epistemic but also a moral question. In other words, they think that to violate an epistemic norm is, by implication, to violate a moral norm. ${ }^{12}$ Later on the same page, they write: 'And, as we saw with Locke and Clifford, that there is such an epistemic norm may be the basis for an argument that there is an analogous moral norm. ${ }^{13}$ In an endnote, they suggest

The latter sort of argument would presumably go like this:

(P1) We have an epistemic obligation not to believe on insufficient evidence;

(P2) We have a moral obligation to uphold our epistemic obligations;

(C) Thus, we have a moral obligation not to believe on insufficient evidence. $^{14}$

This is a mischaracterization of Clifford's original argument in that Clifford does not explicitly or implicitly appeal to the specified premises. Moreover, it is obvious that neither premise plays a role in the arguments for the Cliffordian virtue that have been set out in this paper. In both cases, the inference goes from the idea that there are moral restrictions on acts to the notion that there are derivative moral restrictions on beliefs (because of the relationship between beliefs and acts). In both cases, a detour via purely epistemic norms is unnecessary and unhelpful. Certainly, the arguments for the Cliffordian virtue do not need to be supplemented with the suggested premises. And, as for Clifford's original arguments, Dole and Chignell do not even make an attempt to justify their claim that the presumed reliance exists.

In a different but overlapping piece, Chignell writes that in some places, Clifford seems simply to presume that epistemic duty is a species of ethical duty' and 'elsewhere still Clifford seems not to recognize a distinction between epistemic and moral obligations at all. ${ }^{15}$ It appears that Chignell is so convinced that Clifford must appeal to 'epistemic

${ }^{11}$ Andrew Chignell and Andrew Dole, 'The Ethics of Religious Belief: A Recent History', in Andrew Dole and Andrew Chignell, eds, God and the Ethics of Belief (Cambridge: Cambridge University Press, 2005), pp. 1-27 (p. 4). The quotations come from Chignell's part of the essay - see note 15.

${ }^{12}$ Chignell and Dole, p. 4.

${ }_{13}$ Chignell and Dole, p. 4.

${ }^{14}$ Chignell and Dole, p. 22, n. 14. 
norms' in order to get to moral norms that he thinks that Clifford must use them despite the evidence that he does not use them, or need to use them. Obviously, having asserted that a good philosopher will keep the types of norms distinct, Chignell does effectively suggest that Clifford is confused and that his work is philosophically substandard.

There is, however, one good reason to distinguish moral and epistemic norms. If one assumes that Clifford is trying to establish an epistemic norm or that he must do so to get anywhere with his moral argument against over-believing, then the case for the ethics of belief may appear weaker than it actually is. Consequently, it is worthwhile distinguishing the two to keep Clifford's critics from replacing his actual argument, or the argument for the Cliffordian virtue, with a superficially plausible straw man. Epistemic norms are justified by appeals to the intrinsic value of gaining truth or the value of avoiding falsehood. As William James put it, 'We must know the truth; and we must avoid error - these are our first and great commandments as would-be knowers ... ${ }^{16}$ If Clifford's dictum were just an epistemic norm, it would be justified solely on the basis that it enables us to avoid acquiring false beliefs. The obvious question then would be 'Why is avoiding false beliefs so important?' Critics like James could point out - and do in fact point out - that there are other important goals and complain that avoiding error is not always the most important thing in life. Thereby, Cliffordianism would be made to appear dogmatic, unreasonable, and timorous. Alternatives, in contrast, would be made to seem more plausible. But we have seen that the need for relevant truths provides a reason to develop the Cliffordian virtue. More broadly, the point of the ethics of belief and the Cliffordian virtue is not to exalt one value above a number of competing and equally important values but to promote the moral life itself - not just an aspect of it but the whole of it. It will be recalled that the case for the Cliffordian virtue starts from the general and abstract premise that we have moral obligations.

It is noteworthy that, also in his later piece, Chignell criticizes Clifford but makes no adverse comments on James's arguments, leaving

${ }^{15}$ Andrew Chignell, 'The Ethics of Belief', in The Stanford Encyclopedia of Philosophy, 2010, available at: <http://plato.stanford.edu/entries/ethics-belief/> [accessed 19/11/2011]. This article overlaps with the Chignell and Dole essay in that Chignell, with permission, 're-use[s] a few paragraphs from his portion of the essay ...'

${ }^{16}$ William James, 'The Will to Believe', in his The Will to Believe and Other Essays in Popular Philosophy (Cambridge, MA and London, England: Harvard University Press, 1979), pp. 13-33 (p. 24). 
the impression that James's views are more reasonable than Clifford's, presumably because of his supposed 'moderation'. In fact, James's views are without merit. In his attack on Clifford in 'The Will to Believe', James suggests that his audience will agree that '.. we have the right to believe at our own risk any hypothesis that is live enough to tempt our will. ${ }^{17}$ This appears to be in direct contradiction to Clifford, who argued that we never believe only at our own risk, but James never discusses the risks or suggests ways in which to reduce or eliminate them. What James argues instead is that it is permissible to believe in the case of genuine options, where a genuine option is one that is live, forced, and momentous. An option is live if it appeals to us, it is forced if we must either believe or disbelieve, and it is momentous if it is important enough. In essence, James's view is not that we may believe at our own risk but that we may believe even though we put others at risk, when our own goals are important enough for us. He denies the ethics of belief but ignores the case that Clifford made for it. James is presented as an alternative to Clifford but, although James purports to criticize Clifford, he actually fails to come to grips with Clifford's position.

Not only does James attack a straw man but his positive argument for his own position is questionable. There are no forced options when it comes to believing; hence, there are no genuine options either; and, therefore, the conditions under which he holds it permissible to overbelieve never obtain. A forced option between beliefs is a situation in which one must either believe a proposition or its negation and cannot suspend belief, despite an absence of evidence either way. The obvious problem is that people can always suspend belief when there is no evidence. There are no circumstances in which we entertain a proposition and its negation and in which we cannot say 'I just don't know'.

It is not possible to save James by substituting pragmatic necessity for logical necessity. There are certainly forced options between courses of action. For example, waiting for more information as to whether immediate emergency procedures are necessary is effectively the same as acting as though they are not. Furthermore, it is true that James thinks that believing a proposition is a necessary condition for acting on the assumption that it is true, and it is true that there would be pragmatically forced options between beliefs if he were correct. The problem is that, contrary to James, we never have to believe $p$ in order to act on the

\footnotetext{
${ }^{17}$ James, p. 32; italics in original.
} 
assumption that $p$. Instead of having to work ourselves up into a state of belief, we can simply make assumptions, assumptions that we can then act on without bringing ourselves to believe them. James' view that belief is a prerequisite for action is shown to be false every time a diagnostician knows that a set of symptoms could be explained by a variety of conditions; knows that if a certain condition is the explanation for the symptoms, then a certain treatment will work; applies the treatment; observes the outcome; and thereupon acquires the belief that the suspected condition caused the symptoms or the belief that it did not. The same example confirms the view that we can act on assumptions without believing them. Not even James's famous example of the crevasse-jumper is persuasive. ${ }^{18}$ Someone who knows that he must exert every muscle and sinew to make a leap because the outcome is uncertain will be more highly motivated and hence more likely to succeed than someone who believes that he can make the jump. Finally, even if James were right about the pragmatic need to believe and the desirability of the consequences in some cases, it still would be possible to argue that we should develop the Cliffordian virtue, because the prospective gains from over-believing might well be outweighed by the losses. As we will see in the next section, the supposed gains from over-believing are paltry and speculative.

\section{THE CLIFFORDIAN VIRTUE AND 'PRAGMATIC NORMS'}

There are two types of purported counter-examples that have become standard in the literature that is critical of Clifford. Chignell appeals to them. They purportedly show that 'pragmatic norms' are sometimes more important than moral norms. They are cases in which over-belief is supposedly beneficial.

The first kind of example first appeared in print some thirty years ago. ${ }^{19}$ An example of this kind is provided by the case in which a parent notices an odd smell from an offspring's bedroom. The parent believes that there are at least two possible explanations. One is that the offspring is smoking marijuana. The other is that he or she is burning incense. The parent

${ }^{18}$ William James, 'The Sentiment of Rationality', in his The Will to Believe and Other Essays in Popular Philosophy, pp. 57-89.

${ }^{19}$ Jack W. Meiland, 'What Ought We to Believe?: Or The Ethics of Belief Revisited', American Philosophical Quarterly, 17 (1980), 15-24. It is described as 'the standard example' by Veli Mitova, 'Why W. K. Clifford was a Closet Pragmatist', Philosophical Papers, 37 (2008), 471-489 (p. 473). 
believes that if he or she believes that it is drugs, their relationship with their offspring will be damaged. The parent believes that agnosticism is impossible. The parent wishes to preserve the relationship. Consequently, the parent infers that the offspring is burning incense.

There are a number of problems with this kind of example. First, this is actually an example of taking into account a lucky guess and ignoring denial and delusion. The example does not show that there are never any harmful false beliefs, or that it is possible to avoid the harmful false beliefs other than by avoiding over-belief entirely. It does not even show that the good generally outweighs the bad when it comes to over-believing. Second, the example begs the question in that the good consequences are arbitrarily stipulated rather than flowing naturally from the example. It is also possible that the offspring is smoking marijuana in order to provoke a reaction from the parent, that the offspring wants to provoke a reaction because he or she believes that the parent does not care, and that the offspring wants the parent to care. In that case, the parent's inferring that the offspring is burning incense will damage the relationship further. This underscores the fact that the critic is relying on a lucky guess. Third, the background belief that the parent's relationship with the offspring will be damaged is liable itself to be an over-belief, which means that the example begs the question in yet another way. Fourth, it presupposes that we can believe directly or indirectly at will. Obviously, one can conceive of people inferring that the best explanation for the smell is incense. What one has to imagine is people inferring that it is the best explanation when they also consciously believe that there are at least two equally good explanations, and doing so deliberately. Fifth, it begs the question in that it assumes that the only consequences are the immediate and direct ones. It ignores the fact that Clifford does not hold that all over-beliefs are harmful in themselves. Clifford's objection is that in such cases over-believing still makes us credulous, which puts us at risk of acquiring dangerous beliefs in the future even if the present over-beliefs have no bad consequences. The critic is apparently unaware that someone who makes an inference to the best explanation out of perceived self-interest in one case is liable to make the same kind of inference for the same kind of reason in other cases as well, and that the bad consequences in those cases can outweigh the good consequences in the particular case being considered.

The second kind of 'example' that is taken to support 'pragmatic norms' over moral norms concerns people like the cancer patient who 
supposedly recovers because he believes he will recover. Although it is widely thought that a 'positive attitude' helps, no studies have demonstrated that it causes an improved outcome. If there is a positive correlation between them, it may be that the positive attitude and the improved outcome have a common cause, namely, factors that result in a better chance of recovery. But it is not even clear that there is a positive correlation. There are studies in which a positive attitude is correlated with a worse outcome. ${ }^{20}$ Not only does the positive attitude potentially have a negative effect on the outcome, but also it can have an obviously negative effect on the mental state of the person with cancer (or other condition) by making him feel guilty for not getting well. There is nothing good about making someone feel guilty for not being able to change something that they cannot change.

Earlier in this paper, I presented several examples that showed that over-believing can cause people to violate their moral obligations. The examples are from history and from the contemporary human situation. In contrast, critics of Cliffordianism rely on fictional instances of phenomena that have not yet been shown to occur in the actual world. That is no way to do moral philosophy. Consequentialists could not show that a course of action was the best one by appealing to a mix of real and imaginary consequences and giving the latter the same weight as the former. They should not do so either. The same goes for critics of Cliffordianism.

\section{PETER VAN INWAGEN'S NEW ATTACK}

Peter van Inwagen has produced a new paper attacking Cliffordianism, his argument being based on the existence of philosophical disagreement between equally able and eminent philosophers. ${ }^{21}$ It is similar to the argument he made in a paper published in 1996, in which he argued that Cliffordians unfairly single out the religious for criticism while ignoring people who disagree about political or philosophical issues. ${ }^{22}$

${ }^{20}$ See Barbara Ehrenreich, Smile Or Die: How Positive Thinking Fooled America And The World (London: Granta, 2010).

${ }^{21}$ Peter van Inwagen, 'Listening to Clifford's Ghost', Royal Institute of Philosophy Supplement, 65 (2009), 15-35.

${ }^{22}$ Peter van Inwagen, 'Is It Wrong, Everywhere, Always, and for Anyone, to Believe Anything upon Insufficient Evidence?', in Jeff Jordan, ed., Faith, Freedom, and Rationality: Philosophy of Religion Today (Lanham, Md.: Rowman and Littlefield, 1996), pp. 137-153. 
The unfairness objection is readily refuted. ${ }^{23}$ There is no double standard because many religious over-believers explicitly commend and promote over-belief while the other groups typically neither question nor criticize the desirability of having sufficient evidence for their positions. The Cliffordian is concerned that people accept the ethics of belief. The Cliffordian leaves it up to the participants in the various debates to determine which positions are best supported by the evidence, and that is as it should be. It is therefore natural and understandable that Cliffordians object more strenuously to over-believing religion that commends over-belief than to politics or philosophy.

Furthermore, when Cliffordians object to over-believing religion, they are objecting to the over-believing and not necessarily objecting to the religion. Cliffordianism is not necessarily anti-religious unless religion essentially involves over-belief. It can be added that if God commands us to do good and if over-believing can result in our doing evil despite our good intentions, then God implicitly commands us to avoid overbelieving. It is hardly anti-religious to promote conformity with God's commands. Finally, since the case for it starts with the idea that we have moral obligations to act or to refrain from acting, the Cliffordian virtue can and should function as an auxiliary to any normative moral theory, from which it follows that it can and should function as an auxiliary even to the divine command theory.

At any rate, the conclusion to van Inwagen's new (or renewed) attack is that, in view of the fact that philosophical claims are contested claims, philosophers who do not want to be immoral (because they believe propositions without sufficient evidence) must either believe no philosophical claims at all, or be so arrogant as to think that they are right about every position that they hold. Van Inwagen appears to interpret Cliffordianism as a deontological position and I am willing to concede that van Inwagen succeeds against the deontological Clifford. However, success against deontology does not guarantee success against virtue theory. In light of the ethics of belief qua the need for us all to develop the Cliffordian virtue, no part of van Inwagen's contention holds up. Although the morally optimal state is the one in which a person has no over-beliefs, human beings are limited in their abilities and seldom if ever achieve it. Hence, a person can fail to achieve the morally optimal

${ }^{23}$ See Brian Zamulinski, 'A Re-Evaluation of Clifford and His Critics', Southern Journal of Philosophy, 60 (2002), 437-457. 
state but still be morally blameless - provided he strives to achieve it. Since many philosophers do strive to ensure that their beliefs are adequately supported, they are not all morally blameworthy. Indeed, some may well be exceptionally praiseworthy from a Cliffordian perspective. Moreover, most philosophers surely recognize that human beings (including themselves) have limitations that make it extremely improbable for them to believe that they are always right and that those who disagree with them are always wrong. Any philosopher who displayed the Cliffordian virtue would not maintain such ego-centric views as well. Finally, given that philosophers do strive to provide sufficient evidence (or an adequate substitute) for their claims, it is reasonable to think that some philosophical claims are adequately supported. Since each of van Inwagen's disjuncts is false with respect to the Cliffordian virtue, his disjunction is false as well.

\section{CONCLUSION}

There is a philosophical tradition that tends to portray Clifford as an inconsistent partisan of an epistemically normative doctrine that is so demanding that only ivory-tower intellectuals could find it plausible. We have seen instead that developing the Cliffordian virtue is a necessary condition for living the moral life, whatever it may require of us, and that, far from being excessively demanding, the standards it requires are the same standards commonly required and expected of professionals. We have also seen that a number of objections to it miss the mark and that its incompatibility with religion has been exaggerated. Of course, in all probability, no human being will ever achieve the ideal Cliffordian condition. But ideals are not without value because they are unattainable. On the contrary, they can still function both as guides and as standards for human action. In view of the economic and environmental challenges that humanity now faces, the recognition of the Cliffordian ideal and the development of the Cliffordian virtue seem all the more urgent. Truth always matters and only Cliffordianism gives it its due. 